\title{
Wnt/及-catenin signaling pathway in trophoblasts and abnormal activation in preeclampsia (Review)
}

\author{
ZHAN ZHANG ${ }^{1,2}$, XIAOFANG WANG ${ }^{1}$, LINLIN ZHANG ${ }^{1}$, YING SHI $^{1}$, JINMING WANG $^{3}$ and HUAN YAN ${ }^{3}$ \\ ${ }^{1}$ Department of Clinical Laboratory, The Third Affiliated Hospital of Zhengzhou University, Zhengzhou, Henan 450052; \\ ${ }^{2}$ Department of Clinical Laboratory, Shangqiu Medical College, Shangqiu, Henan 476100; \\ ${ }^{3}$ Department of Obstetrics and Gynecology, The Third Affiliated Hospital of Zhengzhou University, \\ Zhengzhou, Henan 450052, P.R. China
}

Received January 30, 2016; Accepted March 13, 2017

DOI: $10.3892 / \mathrm{mmr} .2017 .6718$

\begin{abstract}
Preeclampsia (PE) is one of the most common types of hypertensive disease and occurs in 3-4\% of pregnancies. There are a number of theories on the pathogenesis of PE. Abnormal differentiation of the placenta may lead to failure of trophoblast migration, shallow placenta implantation and placental ischemia/hypoxia, followed by the subsequent occurrence of $\mathrm{PE}$. The $\mathrm{Wnt} / \beta$-catenin pathway is a canonical Wnt-signaling pathway that regulates several biological processes, including proliferation, migration, invasion and apoptosis. Abnormal activation of the $\mathrm{Wnt} / \beta$-catenin signaling pathway may serve an important role in the pathogenesis of various human diseases, particularly in human cancer. Recent studies have demonstrated that the dysregulation of the Wnt/ $\beta$-catenin signaling pathway may contribute to PE. The present review aims to summarize the articles on Wnt/ $\beta$-catenin signaling pathway in the trophoblast and abnormal activation in PE. Wnt/ $\beta$-catenin signaling may serve a significant role in the pathogenesis of PE and may be a prospective therapeutic target for the prevention and treatment of PE.
\end{abstract}

Correspondence to: Dr Zhan Zhang, Department of Clinical Laboratory, The Third Affiliated Hospital of Zhengzhou University, 7 Kangfu Front Street, Zhengzhou, Henan 450052, P.R. China E-mail: zhangzhanzdsfy@126.com

Abbreviations: APC, adenomatous polyposis coli; CK1, casein kinase 1; CTB, cytotrophoblast; Dkk1, Dickkopf-1; Dvl, disheveled; eCTB, endovascular CTB; EVT, extravillous trophoblast; Fzd, frizzled; GSK3 $\beta$, glycogen synthase kinase $3 \beta$; iCTB, interstitial CTB; LEF, lymphocyte enhancer binding factor; PE, preeclampsia; SFRP, secreted frizzled-related protein; ST, syncytiotrophoblast; TCF, $\mathrm{T}$ cell factor

Key words: Wnt/ $\beta$-catenin, placenta, preeclampsia, trophoblast, invasion

\section{Contents}

1. Introduction

2. Role of trophoblast in preeclampsia

3. Wnt $/ \beta$-catenin signaling pathway

4. Wnt/ $\beta$-catenin signaling pathway in trophoblasts

5 . Wnt $/ \beta$-catenin signaling pathway in the process of preeclampsia

6. Conclusion

\section{Introduction}

Preeclampsia (PE) is as a major factor in maternal and fetal morbidity and mortality. It is one of the most common complications during pregnancy, occurring in $3-4 \%$ of pregnancies, and up to $10 \%$ in developing countries (1). The main clinical presentations are proteinuria, hypertension and edema. Early research focused on understanding hypertension and renal dysfunction; however, additional studies on the syndrome are lacking. Over the past 20 years, increasing evidence has indicated that PE is a multisystemic syndrome that is associated with endothelial dysfunction (2), inflammatory activation (3), an imbalance of angiogenic factors and metabolic changes $(4,5)$. Studies are currently focusing on the process of trophoblast invasion, which is an important feature of PE (6).

Wnt signaling is an essential pathway in the regulation of cell proliferation, migration and death, and is conserved from hydras to humans. Over 30 years ago, Nusse et al (7) identified Wnt genes in mice that lead to tumorigenesis. Since then, an implicit connection has been made between the physiological role of Wnt genes in development and a potential pathophysiological role in carcinogenesis (8). Numerous studies have demonstrated that the Wnt-signaling pathway may lead to a variety of human diseases, ranging from birth defects to cancers, and our previous studies have focused on PE (9-13). Results from one of our previous studies confirmed that the levels of Wnt 2 were decreased in the placenta of patients with $\mathrm{PE}$ (14). Additional experiments are required to investigate the abnormal activation of $\mathrm{Wnt} / \beta$-catenin signaling pathway in PE. 
The present review summarizes recent reports on the pathophysiology of PE, particularly trophoblast invasion, and explores the involvement of $\mathrm{Wnt} / \beta$-catenin signaling pathway in the trophoblast and PE pathophysiology, to further understand the pathogenesis of PE and to discover better treatments.

\section{Role of trophoblast in PE}

The clinical symptoms of PE quickly subside after childbirth. During pregnancy, the placenta acts as an interface between the mother and the fetus, suggesting that the placenta has an important role in PE (15). One highly recognized hypothesis suggests that PE may result from placental dysfunction (16). Development of the human placenta can directly affect the pregnancy outcomes, failure development in placenta can lead pregnant diseases. According to previous clinical, pathological and experimental findings, reduced placental perfusion is the most significant feature of the placenta in PE (17). Placental abnormalities that may be involved in the pathogenic process of PE include abnormal implantation and trophoblast invasion of spiral arterioles, and improper vascular development in the placenta $(18,19)$. A better understanding of abnormal trophoblasts and placentas may contribute to the elucidation of PE pathogenesis.

A previous study revealed that cytotrophoblastic invasion occurs in two stages during pregnancy: Initially after 2 weeks of gestation, and then at 12 and 20 weeks gestation (20). During this time, extravillous cytotrophoblast (CTB) cells invade the maternal spiral uterine arteries. Trophectodermal cells that make up the outer epithelial layer of the blastocyst begin to differentiate into various types of trophoblastic cells after implantation (21). The primitive syncytium, possibly the earliest type of invasive trophoblastic cells are formed by cellular fusions and migrates into the maternal endometrium; CTBs originating from the trophectodermal layer through the primitive syncytium to invade and proliferate which can produce primary villi (22). Subsequent formation of secondary and tertiary villi takes place throughout pregnancy; these villi characteristically invade ectomesenchymal cells, forming villous branches and blood vessels. Two types of mature villi are formed during the first trimester: i) Floating villi, which are the transport units of the human placenta and are directly connected to the intervillous space where nutrients and oxygen are exchanged with maternal blood; and ii) anchoring villi, which can invade the decidua, the muscular layer and blood vessels (23). Interactions between these villi ensure proper fetal development and growth. Villi that are connected to the basal plate of the placenta produce proliferative cell columns, which in turn give rise to differentiated extravillous trophoblast (EVT) cells (24). During the early stages of pregnancy, successful invasion of the endovascular CTB (eCTB) cells and the maternal arterioles may prevent the premature onset of blood flow into the intervillous space (25). Complications during pregnancy may lead to failures in this process, possibly due to premature rises in oxygen levels, which may induce oxidative stress and cause harm to the placental villi (26). Proliferative CTBs differentiate into EVTs and then invade decidual tissue and blood vessels which is thought to encompass a series of precise biological process.
In addition to endovascular invasion, migrating interstitial CTB (iCTB) cells enter the maternal decidua where they are likely to interact with different uterine cell types, such as uterine natural killer cells, macrophages and decidual stromal cells $(27,28)$. These mutual effects have an important role in the immunological acceptance of the placental/fetal allograft and the depth of trophoblast invasion (29). For example, interactions between paternal human leukocyte antigen $\mathrm{C}$ and maternal killer-cell immunoglobulin-like receptors are considered to be important for placentation and reproductive success (30). When blood flow is absent, invasion of the trophoblast is highly dependent on epidermal growth factor and vascular endothelial growth factor (VEGF), which contribute to establishing maternal-placental circulation (31). Once the maternal-placental circulation has formed, the trophoblastic plugs are dissolved and extensive remodeling occurs, including the transformation of maternal spiral arteries into large diameter vessels that ensure an adapted nutrient supply, reduced vessel contractility and constant oxygen delivery to the developing fetus at low blood pressure (32). Natural killer cells and differentiated EVTs may serve a key role in vascular remodeling (33). Maternal endothelial cells are displaced by eCTBs, which then remodel the decidua and myometrium on the surface of the spiral arteries, whereas iCTBs are involved in elastolysis and disruption of the vascular wall, which involves a series of trophoblast-induced events, such as apoptosis of the vascular smooth muscle cells (34). Abnormal vascular pressure may cause hypoxia/reoxygenation injury to floating villi, leading to the secretion of various inflammatory factors and anti-angiogenic molecules, such as interleukin 6, soluble fms-like tyrosine kinase 1 and syncytiotrophoblast (ST) microparticles $(33,35)$. Failures in EVT invasion have been noted in a number of pregnancy-associated diseases, including PE $(36,37)$. Increased ST microparticle shedding is hypothesized to be involved in the dysfunction of maternal endothelial cells, leading to the systemic inflammatory response that may be involved in PE.

\section{Wnt/ $\beta$-catenin signaling pathway}

How Wnt works: Components and mechanism. The first Wnt gene was isolated in 1982 as a common site of integration by the mouse mammary tumor virus and designated Int (38). The gene was later identified to be homologous to the Drosophila segment-polarity gene, wingless (39). The Wnt gene family encode the Wnt proteins that are able to activate intracellular signaling pathway and participate in the development of different mechanisms. The Wnt-signaling pathway is an important regulator of cell proliferation, migration and death, and is conserved from hydras to humans (40). There are three Wnt-signaling pathways in humans: The canonical $\mathrm{Wnt} / \beta$-catenin pathway, the non-canonical $\mathrm{Wnt} / \mathrm{Ca}^{2+}$ pathway and the non-canonical planar cell polarity pathway (41). $\mathrm{Wnt} / \beta$-catenin is a conserved cell-signaling system that is involved numerous biological processes such as organogenesis, axis differentiation in multicellular organisms cancer pathogenesis and the epithelial-mesenchymal transition (42).

Of the three Wnt-signaling pathways, the canonical Wnt/ $\beta$-catenin signaling pathway will be the focus of this review. To date, 19 mammalian Wnt ligands have been 
identified that can directly banding bind to eight out of the 10 frizzled (Fzd) transmembrane G protein-coupled receptors; binding to the Fzd receptor relays the Wnt-signal to the nucleus where it serves its biological role (43). Currently, the most widely studied ligands that can activate the classical Wnt-signaling pathway include Wnt1, Wnt2, Wnt3a and Wnt8. Activation of canonical Wnt signaling is highly dependent on the interactions between Fzd and endogenous co-receptors such as low-density lipoprotein related proteins 5 and 6 (44). $\beta$-catenin also serves an essential role in the function of the Wnt/ $\beta$-catenin signaling pathway. The majority of $\beta$-catenin proteins and epithelial mucins (E-cadherin) are located in the cell membrane, whereas fewer proteins are located in the cytoplasm. When the Wnt ligands are absent (off-state), there are low levels of free $\beta$-catenin in cytoplasm. If not bound to E-cadherin in the cytomembrane, cytoplasmic $\beta$-catenin is phosphorylated by a multiprotein destruction complex [comprising the scaffold proteins axin and adenomatous polyposis coli (APC), and the kinases that phosphorylate $\beta$-catenin, glycogen synthase kinase $3 \beta$ (GSK3 $\beta$ ), casein kinase 1 (CK1) and protein phosphatase $2 \mathrm{~A}]$, which contributes to the degradation of $\beta$-catenin in the cytoplasm through the addition of phosphate groups $(45,46)$. Through this mechanism, the level of $\beta$-catenin in the cytoplasm remains low, and is inhibited from entering the nucleus and thus cannot activate nuclear transcription. Extracellular Wnt proteins bind to the Fzd receptor, which then recruits cytoplasmic proteins and directly binds to Dishevelled (Dvl); Dvl subsequently multimerizes and induces the formation of Wnt signalosomes (Fig. 1) (47). Dvl then recruits axin, which is the rate-limiting component of Wnt/ $\beta$-catenin signaling, and other associated kinases, such as GSK $3 \beta$ and CK1, thus destabilizing the $\beta$-catenin destruction complex. This process leads to the accumulation of $\beta$-catenin in the cytoplasm, which is able to enter the nucleus. In the nucleus, $\beta$-catenin interacts with members of the $\mathrm{T}$ cell factor/ lymphocyte enhancer binding factor family of transcription factors, which can activate the transcription of downstream target genes, such as c-myc, cyclin D1 and matrix metalloproteinase 7 , as transcriptional activator, resulting in the abnormal cellular proliferation and/or apoptosis, along with a series of other biological effects (48).

Functions of Wnt/ $\beta$-catenin signaling. Wnt/ $\beta$-catenin signaling has been demonstrated to contribute to the development of organ systems, including the respiratory, digestive system, skeletal, nervous, cardiovascular, hematopoietic and reproductive systems; in particular, Wnt-signaling is important for the development of the cerebral cortex, heart, skin, teeth, gut, lungs, eyes and lenses, somites, neural crest, limbs, bones, pancreas, liver, kidneys and mammary glands (49-52). Abnormal activation of $\mathrm{Wnt} / \beta$-catenin signaling is implicated in different types diseases, including obstetrical and gynecological disease, metabolic diseases and cancers (53-55).

The Wnt/ $\beta$-catenin signaling pathway is involved in multiple physiological processes, although numerous studies have focused on its role in the pathogenesis of various types of tumor. Aberrant activation of the Wnt/ $\beta$-catenin signaling pathway may result in tumor formation, suggesting that dysfunctional $\mathrm{Wnt} / \beta$-catenin signaling is a significant event that can contribute to the development of cancer (56-59).
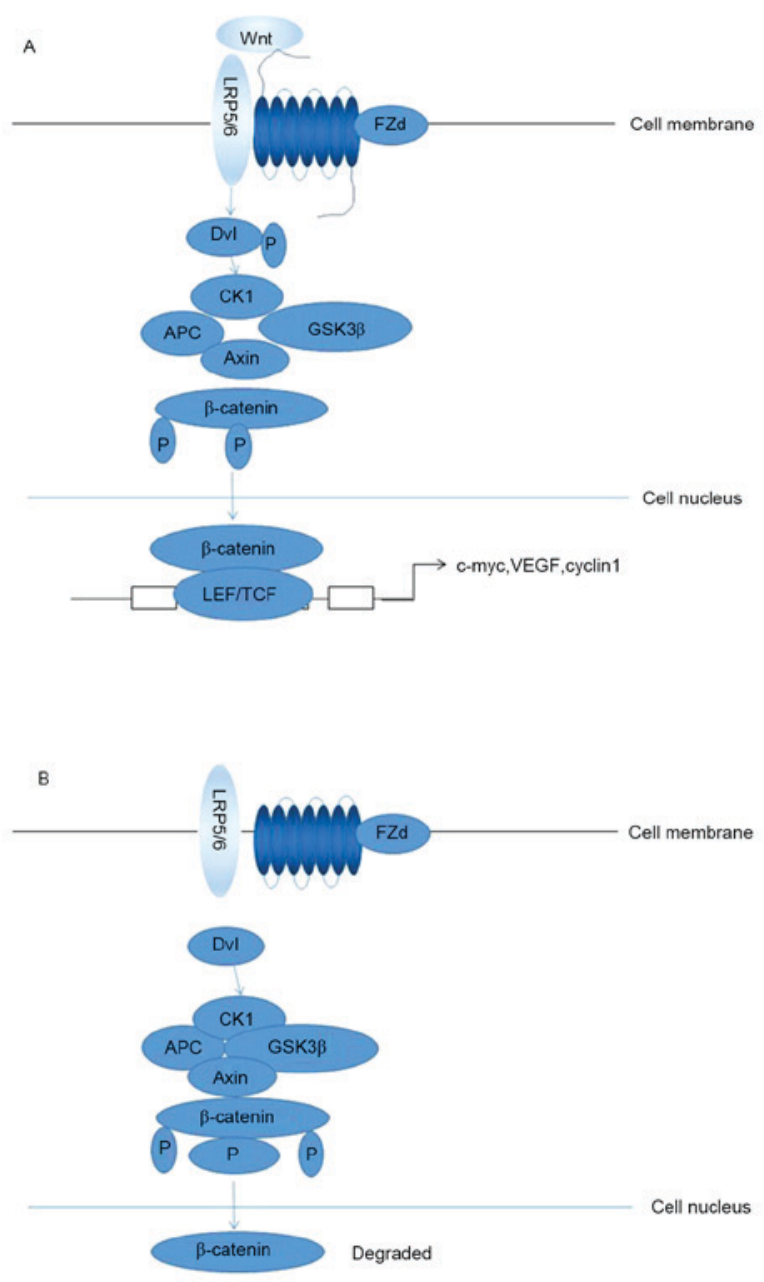

Figure 1 . The transmission mechanism of Wnt/ $\beta$-catenin signaling pathway. (A) In the presence of Wnt, Wnt binding to cell-membrane receptor frees $\beta$-catenin from the complex and prevents its degradation. $\beta$-catenin enter the nucleus to activate target genes. (B) In the absence of Wnt or when Wnt is prevented by an inhibitor, $\beta$-catenin is phosphorylated by a complex. This phosphorylated $\beta$-catenin is rapidly degraded. LRP5/6, low-density lipoprotein receptor-related protein 5/6; Fzd, frizzled; Dvl, disheveled; P, phosphate group; CK1, casein kinase 1; APC, adenomatous polyposis coli; GSK3 $\beta$, GSK $3 \beta$, glycogen synthase kinase $3 \beta$; LEF, lymphocyte enhancer binding factor; TCF, T cell factor; VEGF, vascular endothelial growth factor.

Abnormal activation of the $\mathrm{Wnt} / \beta$-catenin signaling pathway has been linked to primary hepatocellular carcinomas, renal cancer and colorectal cancer, among others (10-13).

\section{Wnt/ $\beta$-catenin signaling pathway in trophoblasts}

The rapid generation of several subtypes of trophoblast cells is well known to contribute to the development of the placenta in mice and humans (60). The maternal uterus is then remodeled, including the stromal cell differentiation, angiogenesis and immunological alterations. These key processes are initiated during the secretory phase of the menstrual cycle, and upon implantation and during the early stages of placental development (24). Since Wnt signaling serves a crucial role in organ development and tissue homeostasis, it is likely that the pathway also has important roles in the development and differentiation of trophoblasts (61). 
A recent study demonstrated that $14 \mathrm{Wnt}$ ligands and eight Fzd receptors are expressed in the human placenta, further indicating a function for the Wnt-signaling pathway in placental development (62). A number of studies have identified Wnt ligands and other Wnt-signaling components in the endometrium, suggesting that the Wnt pathway could be associated with the diverse biological functions of uterine cell types. The expression of Wnt ligand mRNA transcripts has been investigated by microarray analyses of global gene expressions: High levels of Wnt 3 mRNA were detected in the endometrium during the menstrual cycle, whereas the mRNA levels of Dickkopf 1 (Dkk1) increased in in vitro decidualization of endometrial stromal cells in the mid-secretory phase, suggesting a possible role of the Wnt pathway in the differentiation and implantation of the endometrium $(63,64)$. Similarly, a previous study using different trophoblast models have revealed that the Wnt pathway may be closely associated with implantation and the differentiation of trophoblasts (65). Treatment of JAr choriocarcinoma cell spheroids with Dkk1 increased their attachment to Ishikawa endometrial-like adenocarcinoma cells (66). In addition, Wnt4 and Fzd2 expression was shown to be downregulated in primary decidualized endometrial stromal cells, suggesting that trophoblast-dependent Wnt signaling modulates the decidualization process (67).

Wnt signaling serves an essential role in the development of early trophoblasts. Treatment of embryonic stem cells with Wnt3a induced the formation of trophectodermal stem cells that have the ability to differentiate into spongiotrophoblasts (68-70). Several studies have also demonstrated the role of Wnt signaling in the development of extraembryonic tissues; in particular, the vascularization of the placenta $(71,72)$. Krivega et al (73) detected Wnt3 ligands and $\beta$-catenin in human blastocysts, and demonstrated that they could promote progenitor trophoblast development during embryogenesis. Wnt signaling has been indicated to function during trophoblast differentiation. For example, Meinhardt et al (74) suggested that the Wnt-signaling pathway may play a role in EVT differentiation by downregulating of TCF4. A role for Wnt signaling during invasion was demonstrated in vivo as well as in vitro, depending on the level of nuclear $\beta$-catenin expression by explanting cultures the chorionic villous (75). Furthermore, stimulation with Wnt ligand was revealed to increase the invasion of primary CTBs (24). However, the ability of cells to migrate and invade decreased in the different trophoblast models treated with recombinant Dkk1, suggesting that the canonical Wnt proteins that are expressed in EVTs exert autocrine effects (76). Wnt-Fzd5 signaling may lead to the upregulation of VEGF expression in the chorion and the subsequent vascularization of primary villi, suggesting that Fzd5 is involved in human trophoblast differentiation (77).

Wnt signaling also contributes to trophoblast invasion. One study demonstrated high levels of $\beta$-catenin-positive EVT nuclei in the placenta of complete hydatidiform moles (CHMs), compared to normal cells, indicating that dysregulated Wnt signaling could contribute to abnormal trophoblast development (78). As Dkk1 inhibits canonical Wnt signaling, the pathway may decrease the invasion of trophoblast cells. Ectoplacental cones co-cultured with decidual cells were demonstrated to promoted trophoblast invasion when treated with recombinant Dkk1, whereas treatment with Dkk1 antibodies and antisense oligonucleotides reduced invasiveness (79). $\beta$-catenin activation is a strong promoter of HTR8/ SVneo cell (normal trophoblast cell line) invasion, leading to the outgrowth and migration in villous explants (80). The levels of Wnt1, Wnt7A, Wnt10A and Wnt10B expression were revealed to be higher in first trimester trophoblasts compared with term trophoblasts, whereas Wnt1 and Wnt2B were more strongly expressed in EVTs, suggesting that Wnt may regulate trophoblast invasiveness (62). Hyperactivation of Wnt $/ \beta$-catenin signaling may lead to trophoblast disorders such as choriocarcinoma, whereas the downregulation of Wnt $/ \beta$-catenin signaling may lead to PE.

Recent epigenetic studies have demonstrated a general level of activation of Wnt signaling in isolated trophoblasts $(81,82)$. As important components of the Wnt signaling pathway, APC and secreted Fzd-related protein 2 (sFRP2) were revealed to be hypermethylated in trophoblasts compared with the placental fibroblasts or leukocytes (83). This finding suggested that activation of the Wnt-signaling pathway in trophoblasts may contribute to placentation. Effectors other than Wnt ligands are likely to serve a role in the stabilization of $\beta$-catenin, as well as the proliferation and invasion of trophoblasts. A study demonstrated that Dkk1 is able to induce apoptosis and inhibit proliferation in JEG3 and BeWo trophoblast cell lines (84). The expression levels of Dkk1 and sFRP4 were demonstrated to be higher in PE compared with normal placental tissues, whereas the levels of Wnt 2 and $\beta$-catenin expression were decreased $(14,16)$, indicating that the Wnt-signaling pathway may serve a role in the development of placental tissues.

\section{Wnt/ $\beta$-catenin signaling pathway in the process of $\mathrm{PE}$}

$\mathrm{PE}$ is a major cause of maternal and perinatal morbidity and mortality in developing countries (14). To reduce the danger of this disease, the most important task is to determine the pathogenesis of $\mathrm{PE}$, of which there are various theories. Although the precise underlying molecular mechanisms for PE remain unknown, endothelial cell dysfunction, maternal-fetal immune balance disorders, inflammation and abnormal recasting of blood vessels are considered to contribute to PE (85-87). Numerous placenta-induced factors appear in PE, such as shallow placenta implantation, an imbalance between trophoblast proliferation and apoptosis $(88,89)$. An improved understanding of the nature of the placenta can help us to identify which factor lead to the PE (90). It is speculated that humans have the tendency to develop PE for a number of reasons, but the following factors are essential for PE development: Trophoblast differentiation disorder, hypoxia-ischemia of the placenta and the extent of trophoblast-induced uterine artery transformation.

Trophoblasts are a highly specialized cell type. They grow faster than normal cells and they have the ability to migrate and invade maternal myometrium, which is similar to the process in which tumor cells invade the surrounding tissue. However, trophoblast migration is tightly controlled by the body, both temporally and spatially, which is an essential difference compared with tumor cell migration. There are two types of trophoblastic cells: CTBs and STs. With further advances, lymphocyte proliferation could be inhibited by artificially generated CTB membrane fragments, and leading to T lymphocyte 
apoptosis, which may damage the formation of endothelial cell monolayers and then contribute the pathogenesis of PE (91). It is increasingly accepted that CTBs contribute to PE.

In a normal pregnancy, during the process of the placental formation, the Sertoli cell matrix of spiral arteries is transformed into large-capacity, low-resistance blood vessels during a normal pregnancy (25). This ensures the nutrition of the fetus and the demand for oxygen are adequately met. Abnormal Sertoli cell differentiation can interfere with their function, damage trophoblast migration ability, cause disorder to the invasion of the myometrium, cause shallow placenta implantation, lead to placental ischemia-hypoxia and induce PE.

To date, the factors governing blastocyst activation remain poorly understood; however, recent studies have shown that multiple signaling pathways are involved in regulating the differentiation, apoptosis and invasion of trophoblasts $(24,92,93)$. Advances in our understanding of normal nourishing cells revealed some unique biological characteristics that are more similar to malignant tumors. Activation of the Wnt/ $\beta$-catenin signaling pathway promotes tumor cell apoptosis (53). It has been hypothesized that the Wnt/ $\beta$-catenin signaling pathway may also affect blastocysts and may be the main cause for shallow trophoblast invasion and disruption to the remodeling of the spiral artery, which is one of the most essential and crucial pathological changes that occurs during PE and is followed by a series of complications.

Wnt-signaling components were revealed to be involved in the pathogenesis of various diseases, including gestational diseases. $\beta$-catenin-positive EVT nuclei were detected at higher levels in the placenta of a CHM compared with normal tissues, indicating that improper Wnt signaling could lead to abnormal invasion and differentiation in CHM. APC and sFRP2 genes were revealed to be hypermethylated in choriocarcinoma cells, suggesting that the inactivation of Wnt signaling may serve a major role in the pathogenesis of trophoblastic cancer cells (82).

The expression levels of Dkk1 and sFRP4 were increased in placental tissues from patients with $\mathrm{PE}$, whereas the levels of Wnt 2 and $\beta$-catenin expression were reduced $(14,16)$. Results from our previous study revealed a stronger expression of E-cadherin in the cytomembrane of villous ST and EVT in PE tissue, compared with normal tissue (94). These results provide direct evidence that the Wnt-signaling pathway is closely associated with PE.

\section{Conclusion}

Canonical Wnt/ $\beta$-catenin signaling is an essential pathway that promotes implantation, blastocyst activation and implantation. It serves crucial roles in the differentiation, differentiation and invasion of trophoblasts. Abnormal Wnt/ $\beta$-catenin signaling was observed in numerous diseases including $\mathrm{PE}$, which is one of the major causes of the perinatal morbidity and mortality. A better understanding of PE pathogenesis is essential and may reduce the mortality of the fetus and the mother. In this review, recent studies that have investigated the pathophysiology of $\mathrm{PE}$ were examined; in particular, those concerning the possible role of $\mathrm{Wnt} / \beta$-catenin signaling pathway were reviewed in detail. A number of studies suggest that the $\mathrm{Wnt} / \beta$-catenin signaling pathway may have an essential role in the trophoblast and the development of PE. However, direct evidence of a role for Wnt/ $\beta$-catenin signaling pathway in the development of PE is lacking. Future studies will help verify whether Wnt $/ \beta$-catenin signaling within trophoblasts participates in the development of PE.

\section{Acknowledgements}

The present study was supported by the National Natural Science Foundation (grant no. 81501285).

\section{References}

1. Wang A, Rana S and Karumanchi SA: Preeclampsia: The role of angiogenic factors in its pathogenesis. Physiology (Bethesda) 24: 147-158, 2009.

2. Roberts JM, Taylor RN, Musci TJ, Rodgers GM, Hubel CA and McLaughlin MK: Preeclampsia: An endothelial cell disorder. Am J Obstet Gynecol 161: 1200-1204, 1989.

3. Redman CW, Sacks GP and Sargent IL: Preeclampsia: An excessive maternal inflammatory response to pregnancy. Am J Obstet Gynecol 180: 499-506, 1999.

4. Mongraw-Chaffin ML, Cirllo PM and Cohn BA: Preeclampsia and cardiovascular disease death: Prospective evidence from the child health and development studies cohort. Hypertension 56: 166-171, 2010.

5. Hubel CA, McLaughlin MK, Evans RW, Hauth BA, Sims CJ and Roberts JM: Fasting serum triglycerides, free fatty acids, and malondialdehyde are increased in preeclampsia, are positively correlated, and decrease within 48 hours post partum. Am J Obstet Gynecol 174: 975-782, 1996.

6. Kaufmann P, Black S and Huooertz B: Endovascular trophoblast invasion: Implications for the pathogenesis of intrauterine growth retardation and preeclampsia. Biol Reprod 69: 1-7, 2003.

7. Nusse R, van Ooyen A, Cox D, Fung YK and Varmus H: Mode of proviral activation of a putative mammary oncogene (int-1) on mouse chromosome 15. Nature 307: 131-136, 1984.

8. Saito-Diaz K, Chen TW, Wang X, Thorne CA, Wallace HA, Page-McCaw A and Lee E: The way Wnt works: Components and mechanism. Growth Factors 31: 1-31, 2013.

9. Sonderegger S, Pollheimer J and Knöfler M: Wnt signalling in implantation, decidualisation and placental differentiation-review. Placenta 31: 839-847, 2010.

10. Ma XR, Edmund Sim UH, Pauline B, Patricia L and Rahman J: Overexpression of WNT2 and TSG101 genes in colorectal carcinoma. Trop Biomed 25: 46-57, 2008.

11. Geng M, Cao YC, Chen YJ, Jiang H, Bi LQ and Liu XH: Loss of Wnt5a and Ror2 protein in hepatocellular carcinoma associated with poor prognosis. World J Gastroenterol 18: 1328-1338, 2012.

12. Bui TD, Zhang L, Rees MC, Bicknell R and Harris AL: Expression and hormone regulation of $\mathrm{Wnt} 2,3,4,5 \mathrm{a}, 7 \mathrm{a}, 7 \mathrm{~b}$ and $10 \mathrm{~b}$ in normal human endometrium and endometrial carcinoma. Br J Cancer 75: 1131-1136, 1997.

13. Hirata H, Hinoda Y, Nakajima K, Kawamoto K, Kikuno N, Ueno K, Yamamura S, Zaman MS, Khatri G, Chen Y, et al: Wnt antagonist DKK1 acts as a tumor suppressor gene that induces apoptosis and inhibits proliferation in human renal cell carcinoma. Int J Cancer 128: 1793-1803, 2011.

14. Zhang Z,Zhang L, Zhang L, Jia L, Wang P and Gao Y: Association of Wnt 2 and sFRP4 Expression in the Third trimester placenta in women with severe preeclampsia. Reprod Sci 20: 981-989, 2013.

15. Roberts JM and Escudero C: The placenta in preeclampsia. Pregnancy Hypertens 2: 72-83, 2012.

16. Zhang Z, Li H,Zhang L, Jia L and Wang P: Differential expression of beta-catenin and dickkopf-1 in the third trimester placentas from normal and preeclamptic pregnancies: A comparative study. Reprod Biol Endocrinol 11: 17, 2013.

17. Roberts JM and Gammill HS: Preeclampsia: Recent insights. Hypertension 46: 1243-1249, 2005.

18. LaMarca BD, Gilbert J and Granger JP: Recent progress toward the understanding of the pathophysiology of hypertension during preeclampsia. Hypertension 51: 982-988, 2008.

19. Red-Horse K, Zhou Y, Genbacev O, Prakobphol A, Foulk R, McMaster $\mathrm{M}$ and Fisher SJ: Trophoblast differentiation during embryo implantation and formation of the maternal-fetal interface. J Clin Invest 114: 744- 754, 2004. 
20. Singh HJ: Pre-eclampsia: Is it all in the placenta? Malays J Med Sci 16: 7-15, 2009.

21. Cross JC, Werb Z and Fisher SJ: Implantation and the placenta: Key pieces of the development puzzle. Science 266: 1508-1518, 1994.

22. Carter AM, Enders AC and Pijnenborg R: The role of invasive trophoblast in implantation and placentation of primates. Philos Trans R Soc Lond B Biol Sci 370: 20140070, 2015.

23. Caniggia I, Winter J, Lye SJ and Post M: Oxygen and placental development during the first trimester: Implications for the pathophysiology of pre-eclampsia. Placenta 21 (Suppl A): S25-S30, 2000.

24. Knöfler M and Pollheimer J: Human placental trophoblast invasion and differentiation: A particular focus on Wnt signaling. Front Genet 4: 190, 2013.

25. Pijnenborg R, Vercruysse L and Hanssens M: The uterine spiral arteries in human pregnancy: Facts and controversies. Placenta 27: 939-958, 2006.

26. Jauniaux E, Hempstock J, Greenwold N and Burton GJ: Trophoblastic oxidative stress in relation to temporal and regional differences in maternal placental blood flow in normal and abnormal early pregnancies. Am J Pathol 162: 115-125, 2003.

27. Bulmer JN, Williams PJ and Lash GE: Immune cells in the placental bed. Int J Dev Biol 54: 281-294, 2010.

28. Oreshkova T, Dimitrov R and Mourdjeva M: A cross-talk of decidual stromal cells, trophoblast, and immune cells: A prerequisite for the success of pregnancy. Am J Reprod Immunol 68: 366-373, 2012.

29. Rauwel B, Mariamè B, Martin H, Nielsen R, Allart S, Pipy B, Mandrup S, Devignes MD, Evain-Brion D, Fournier T and Davrinche C: Activation of peroxisome proliferator-activated receptor gamma by human cytomegalovirus for de novo replication impairs migration and invasiveness of cytotrophoblasts from early placentas. J Virol 84: 2946-2954, 2010.

30. Hiby SE, Walker JJ, O'shaughnessy KM, Redman CW, Carrington M, Trowsdale $\mathrm{J}$ and Moffett A: Combinations of maternal KIR and fetal HLA-C genes influence the risk of preeclampsia and reproductive success. J Exp Med 200: 957-965, 2004.

31. Burton GJ, Jauniaux E and Charnock-Jones DS: Human early placental development: Potential roles of the endometrial glands. Placenta 28 (Suppl A): S64-S69, 2007.

32. Burton GJ, Jauniaux E and Charnock-Jones DS: The influence of the intrauterine environment on human placental development. Int. Int J Dev Biol 54: 303-312, 2010.

33. Robson A, Harris LK, Innes BA, Lash GE, Aljunaidy MM, Aplin JD, Baker PN, Robson SC and Bulmer JN: Uterine natural killer cells initiate spiral artery remodeling in human pregnancy. FASEB J 26: 4876-4885, 2012.

34. Harris LK: IFPA Gabor Than Award lecture: Transformation of the spiral arteries in human pregnancy: Key events in the remodelling timeline. Placenta 32 (Suppl 2): S154-S158, 2012.

35. Tal R: The role of hypoxia and hypoxia-inducible factor-1alpha in preeclampsia pathogenesis. Biol Reprod 87: 134, 2012.

36. Pijnenborg R, Anthony J, Davey DA, Rees A, Tiltman A, Vercruysse L and van Assche A: Placental bed spiral arteries in the hypertensive disorders of pregnancy. Br J Obstet Gynaecol 98: 648-655, 1991

37. Zhou Y, Gormley MJ, Hunkapiller NM, Kapidzic M, Stolyarov Y, Feng V, Nishida M, Drake PM, Bianco K, Wang F, et al: Reversal of gene dysregulation in cultured cytotrophoblasts reveals possible causes of preeclampsia. J Clin Invest 123: 2862-2872, 2013.

38. Nusse R and Varmus HE: Many tumors induced by the mouse mammary tumor virus contain a provirus integrated in the same region of the host genome. Cell 31: 99-109, 1982.

39. Clevers H: Wnt/beta-catenin signaling in development and disease. Cell 127: 469-480, 2006.

40. Miller JR: The Wnts. Genome Biol 3: REVIEWS3001, 2002.

41. Kestler HA and Kühl M: From individual Wnt pathways towards a Wnt signalling network. Philos Trans R Soc Lond B Biol Sci 363: 1333-1347, 2008 .

42. Bender W and Reifer M: Oncogenes take wing. Cell 50: 519-520, 1987.

43. Wodarz A and Nusse R: Mechanisms of Wnt signaling in development. Annu Rev Cell Dev Biol 14: 59-88, 1998.

44. Ng SS, Mahmoudi T, Danenberg E, Bejaoui I, de Lau W, Korswagen HC, Schutte M and Clevers H: Phosphatidylinositol 3-kinase signaling does not activate the Wnt cascade. J Biol Chem 284: 35308-35313, 2009.
45. Valenta T, Hausmann G and Basler K: The many faces and functions of $\beta$-catenin. EMBO J 31: 2714-2736, 2012.

46. Kimelman D and Xu W: beta-catenin destruction complex: Insights and questions from a structural perspective. Oncogene 25: 7482-7491, 2006.

47. Wong HC, Bourdelas A, Krauss A, Lee HJ, Shao Y, Wu D, Mlodzik M, Shi DL and Zheng J: Direct binding of the PDZ domain of Dishevelled to a conserved internal sequence in the C-terminal region of Frizzled. Mol Cell 12: 1251-1260, 2003.

48. Jho EH, Zhang T, Domon C, Joo CK, Freund JN and Costantini F: Wnt/beta-catenin/Tef signaling induces the transcription of Axin2, a negative regulator of the signaling pathway. Mol Cell Biol 22: 1172-1183, 2002.

49. Logan CY and Nusse R: The Wnt signaling pathway in development and disease. Annu Rev Cell Dev Biol 20: 781-810, 2004.

50. Cadigan KM and Peifer M: Wnt signaling from development to disease: Insights from model systems. Cold Spring Harb Perspect Biol 1: a002881, 2009.

51. van Amerongen R and Nusse R: Towards an integrated view of Wnt signaling in development. Development 136: 3205-3214, 2009.

52. MacDonald BT, Tamai K and He X: Wnt/beta-catenin signaling: Components, mechanisms, and diseases. Dev Cell 17: 9-26, 2009.

53. Polakis P: The many ways of Wnt in cancer. Curr Opin Genet Dev 17: 45-51, 2007.

54. Clevers $\mathrm{H}$ and Nusse $\mathrm{R}$ : Wnt/ $\beta$-catenin signaling and disease. Cell 149: 1192-1205, 2012.

55. Polakis P: Drugging Wnt signalling in cancer. EMBO J 31: 2737-2746, 2012.

56. Chien AJ, Conrad WH and Moon RT: A Wnt survival guide: From flies to human disease. J Invest Dermatol 129: 1614-1627, 2009.

57. Giles RH, van Es JH and Clevers H: Caught up in a Wnt storm: Wnt signaling in cancer. Biochim Biophys Acta 1653: 1-24, 2003.

58. Phelps RA, Broadbent TJ, Stafforini DM and Jones DA: New perspectives on APC control of cell fate and proliferation in colorectal cancer. Cell Cycle 8: 2549-2556, 2009.

59. Tarapore RS, Siddiqui IA and Mukhtar H: Modulation of Wnt/ $\beta$-catenin signaling pathway by bioactive food components. Carcinogenesis 33: 483-491, 2012.

60. Georgiades P, Ferguson-Smith AC and Burton GJ: Comparative developmental anatomy of the murine and human definitive placentae. Placenta 23: 3-19, 2002.

61. Gough NR: Focus issue: Wnt and $\beta$-catenin signaling in development and disease. Sci Signal 5: eg2, 2012.

62. Sonderegger S, Husslein H, Leisser C and Knöfler M: Complex expression pattern of Wnt ligands and frizzled receptors in human placenta and its trophoblast subtypes. Placenta 28 (Suppl A): S97-S102, 2007.

63. Tulac S, Nayak NR, Kao LC, Van Waes M, Huang J, Lobo S, Germeyer A, Lessey BA, Taylor RN, Suchanek E and Giudice LC: Identification, characterization, and regulation of the canonical Wnt signaling pathway in human endometrium. J Clin Endocrinol Metab 88: 3860-3866, 2003.

64. Carson DD, Lagow E, Thathiah A, A1-Shami R, Farach-Carson MC, Vernon M, Yuan L, Fritz MA and Lessey B: Changes in gene expression during the early to mid-luteal (receptive phase) transition in human endometrium detected by high-density microarray screening. Mol Hum Reprod 8: 871-879, 2002.

65. Chen Y, Zhang Y, Deng Q, Shan N, Peng W, Luo X, Zhang H, Baker PN, Tong C and Qi H: Wnt5a inhibited human trophoblast cell line HTR8/SVneo invasion: Implications for early placentation and preeclampsia. J Matern Fetal Neonatal Med 29: 3532-3538, 2016.

66. Liu Y, Kodithuwakku SP, Ng PY, Chai J, Ng EH, Yeung WS, Ho PC and Lee KF: Excessive ovarian stimulation up-regulates the Wnt-signaling molecule DKK1 in human endometrium and may affect implantation: An in vitro co-culture study. Hum Reprod 25: 479-490, 2010.

67. Hess AP, Hamilton AE, Talbi S, Dosiou C, Nyegaard M, Nayak N, Genbecev-Krtolica O, Mavrogianis P, Ferrer K, Kruessel J, et al: Decidual stromal cell response to paracrine signals from the trophoblast: Amplification of immune and angiogenic modulators. Biol Reprod 76: 102-117, 2007.

68. Chawengsaksophak K, de Graaff W, Rossant J, Deschamps J and Beck F: Cdx2 is essential for axial elongation in mouse development. Pro Natl Acad Sci USA 101: 7641-7645, 2004.

69. Miller C and Sassoon DA: Wnt-7a maintains appropriate uterine patterning during the development of the mouse female reproductive tract. Development 125: 3201-3211, 1998. 
70. Vainio S, Heikkilä M, Kispert A, Chin N and McMahon AP: Female development in mammals is regulated by Wnt-4 signalling. Nature 397: 405-409, 1999.

71. Newman AC and Hughes CC: Macrophages and angiogenesis: A role for Wnt signaling. Vasc Cell 4: 13, 2012.

72. Herr F, Horndasch M, Howe D, Baal N, Goyal P, Fischer S, Zygmunt $\mathrm{M}$ and Preissner KT: Human placenta-derived Wnt-5a induces the expression of ICAM-1 and VCAM-1 in CD133(+) CD34(+)-hematopoietic progenitor cells. Reprod Biol 14: $262-275,2014$.

73. Krivega M, Essahib W and Van de Velde H: WNT3 and membrane-associated $\beta$-catenin regulate trophectoderm lineage differentiation in human blastocysts. Mol Hum Repro 21: 711-722, 2015.

74. Meinhardt G, Haider S, Haslinger P, Proestling K, Fiala C Pollheimer $\mathrm{J}$ and Knöfler M: Wnt-dependent T-cell factor-4 controls human extravillous trophoblast motility. Endocrinology 155: 1908-1920, 2014.

75. Bilic J, Huang YL, Davidson G, Zimmermann T, Cruciat CM, Bienz $M$ and Niehrs C: Wnt induces LRP6 signalosomes and promotes dishevelled-dependent LRP6 phosphorylation. Science 316: 1619-1622, 2007.

76. Sonderegger S, Haslinger P, Sabri A, Leisser C, Otten JV, Fiala C and Knöfler M: Wingless (Wnt)-3A, induces trophoblast migration and matrix metalloproteinase-2 secretion through canonical Wnt signaling and protein kinase B/AKT activation. Endocrinology 151: 211-220, 2010.

77. Lu J, Zhang S, Nakano H, Simmons DG, Wang S, Kong S, Wang Q, Shen L, Tu Z, Wang W, et al: A positive feedback loop involving $\mathrm{Gcm} 1$ and Fzd5 directs chorionic branching morphogenesis in the placenta. PLoS Biol 11: e1001536, 2013.

78. Pollheimer J, Loregger T, Sonderegger S, Saleh L, Bauer S Bilban M, Czerwenka K, Husslein P and Knöfler M: Activation of the canonical wingless/T-cell factor signaling pathway promotes invasive differentiation of human trophoblast. Am J Pathol 168: 1134-1147, 2006

79. Peng S, Li J, Miao C, Jia L, Hu Z, Zhao P, Li J, Zhang Y, Chen Q and Duan E: Dickkopf-1 secreted by decidual cells promotes trophoblast cell invasion during murine placentation. Reproduction 135: 367-75, 2008.

80. Zhuang B, Luo X, Rao H, Li Q, Shan N, Liu X and Qi H: Oxidative stress-induced C/EBP $\beta$ inhibits $\beta$-catenin signaling molecule involving in the pathology of preeclampsia. Placenta 36 : 839-846, 2015

81. Lavergne E, Hendaoui I, Coulouarn C, Ribault C, Leseur J, Eliat PA, Mebarki S, Corlu A, Clément B and Musso O: Blocking Wnt signaling by SFRP-like molecules inhibits in vivo cell proliferation and tumor growth in cells carrying active $\beta$-catenin. Oncogene 30: 423-433, 2011.
82. Wong NC, Novakovic B, Weinrich B, Dewi C, Andronikos R, Sibson M, Macrae F, Morley R, Pertile MD, Craig JM and Saffery R: Methylation of the adenomatous polyposis coli (APC) gene in human placenta and hypermethylation in choriocarcinoma cells. Cancer Lett 268: 56-62, 2008.

83. Novakovic B, Rakyan V, Ng HK, Manuelpillai U, Dewi C, Wong NC, Morley R, Down T, Beck S, Craig JM and Saffery R: Specific tumour-associated methylation in normal human term placenta and first-trimester cytotrophoblasts. Mol Hum Reprod 14: 547-554, 2008.

84. Cui H, Li H, Li QL, Chen J, Na Q and Liu CX: Dickkopf-1 induces apoptosis in the JEG3 and BeWo trophoblast tumor cell lines through the mitochondrial apoptosis pathway. Int $\mathrm{J}$ Oncol 46: 2555-2561, 2015.

85. Ducat A, Doridot L, Calicchio R, Méhats C, Vilotte JL, Castille J, Barbaux S, Couderc B, Jacques S and Letourneur F, et al: Endothelial cell dysfunction and cardiac hypertrophy in the STOX1 model of preeclampsia. Sci Rep 6: 19196, 2016.

86. Szarka A, Rigó J Jr, Lázár L, Beko G and Molvarec A: Circulating cytokines, chemokines and adhesion molecules in normal pregnancy and preeclampsia determined by multiplex suspension array. BMC Immunol 11: 59, 2010

87. Crocker I: Gabor Than Award Lecture 2006: pre-eclampsia and villous trophoblast turnover: perspectives and possibilities. Placenta 28 (Suppl A): S4-S13, 2007.

88. Goldman-Wohl D and Yagel S: Regulation of trophoblast invasion: From normal implantation to pre-eclampsia. Mol Cell Endocrinol 187: 233-238, 2002.

89. Can M, Guven B, Bektas S and Arikan I: Oxidative stress and apoptosis in preeclampsia. Tissue Cell 46: 477-481, 2014.

90. Schrocksnadel H, Daxenbichler G, Artner E, Steckel-Berger G and Dapunt O: Tumor markers in hypertensive disorders of pregnancy. Gynecol Obstet Invest 35: 204-208, 1993.

91. Dey SK, Lim H, Das SK, Reese J, Paria BC, Daikoku T and Wang H: Molecular cues to implantation. Endocr Rev 25: 341-373, 2004.

92. Zhang J, Dunk CE and Lye SJ: Sphingosine signaling regulates decidual NK cell angiogenic phenotype and trophoblast migration. Hum Reprod 28: 3026-3037, 2013.

93. Fan M, Xu Y, Hong F, Gao X, Xin G, Hong H, Dong L and Zhao X: Rac1//-catenin signalling pathway contributes to trophoblast cell invasion by targeting snail and MMP9. Cell Physiol Biochem 38: 1319-1332, 2016

94. Zhang Zhan, LI Wei, Zhang Lin-Lin, Jia Li-Ting, Yu Hai-Yang and Liu Li-Sha: Detection of E-cadherin expression in preeclampsia by placenta tissue microarray. Chinese Journal of Health Laboratory Technology 9: 1232-1235, 2014. 